s..

NASA CONTRACTOR REPORT

$\frac{m}{\alpha}$
$\vdots$
$\vdots$
$\vdots$
$\vdots$
$\Sigma$

LOAN COPY: RETURN TO AFWL (WLIL-2)

KIRTLAND AFB, N MEX

\title{
THE PRINCIPLE OF \\ THE SPACE ACTIVITY SUIT
}

by Paul Webb, M.D., and James F. Annis

\section{Prepared by}

WEBB ASSOCIATES, INC.

Yellow Springs, Ohio

for-Langley Research Center

NATIONAL AERONAUTICS AND SPACE ADMINISTRATION - WASHINGTON, D. C. - DECEMBER 1967 
Distribution of this report is provided in the interest of information exchange. Responsibility for the contents resides in the author or organization that prepared it.

Prepared under Contract No. NAS 1-6872 by WEBB ASSOCIATES, INC.

Yellow Springs, Ohio

for Langley Research Center

NATIONAL AERONAUTICS AND SPACE ADMINISTRATION

For sale by the Clearinghouse for Federal Scientific and Technical Information Springfield, Virginia 22151 - CFSTI price $\$ 3.00$ 


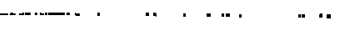




\section{A.BSTRACT}

This paper describes in principle a Space Activity Suit (SAS) designed for an active astronaut working in a vacuum for up to four hours. The suit will consist of a powerful elastic net leotard combined with positive pressure breathing via helmet and trunk bladders.

Under the terms of the present contract, an elastic sleeve-and-glove was constructed to demonstrate the principle of the full SAS suit. Subjects wore the garment in an arm chamber which produced negative pressures up to $200 \mathrm{~mm} \mathrm{Hg}$ ( 8 in $\mathrm{Hg}$ ). Exposures to near-vacuum conditions were accomplished in an altitude chamber where the total pressure was $155 \mathrm{~mm} \mathrm{Hg}$ and the arm chamber pressure was 5 to $8 \mathrm{~mm} \mathrm{Hg}$. The near-vacuum exposure for 20 minutes produced no evidence of gaseous swelling; arterial and venous circulation was adequate; mobility and finger dexterity were excellent; increase in arm volume from accumulation of tissue fluid was approximately $5 \%$.

The successful demonstration of principle indicates that a full SAS can be developed. A.s an alternative to gas-filled pressure suits, its advantages would be: improved mobility, flexibility, and dexterity at small metabolic cost; simplicity in approach; low risk to the astronaut if the netting is torn; and physiological temperature regulation without power or cooling machinery. 


\section{TABLE OF CONTENTS}

SUMMARY

page no.

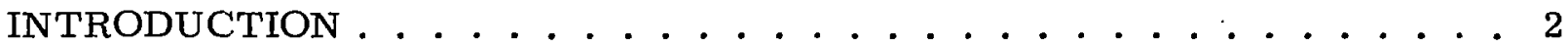

Problems of Mobility in Full Pressure Suits . . . . . . . . . . 2

Basis of the SAS Approach . . . . . . . . . . . . . . 2

Scope ...................... . . 4

SAS DESIGN PRINCIPLES . . . . . . . . . . . . . . . . . . . 4

MAINTENANCE OF PHYSIOLOGICAL FUNCTIONS . . . . . . . . . . 6

The Mechanics of Respiration . . . . . . . . . . . . 6

The Circulatory System . . . . . . . . . . . . . 6

Thermoregulation ................ 6

POSITIVE PRESSURE BREATHING WITH MECHANICAL PRESSURE . . . 7

EXPERIMENTAL DEMONSTRATION OF PRINCIPLE . . . . . . . . . . . . 8

Method of Sleeve Construction . . . . . . . . . . . . . . 9

Choice of material. . . . . . . . . . . . . . . 9

Pattern making . . . . . . . . . . . . . . . 9

Sewing . . . . . . . . . . . . . . . . . 9

Soft joints and special fills . . . . . . . . . . . . 10

Arm Chamber . . . . . . . . . . . . . . . . 11

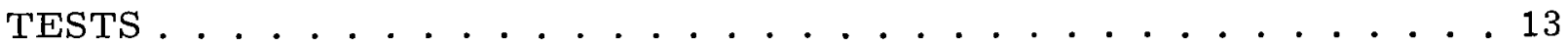

RESULTS . . . . . . . . . . . . . . . . . . 17

Effects of Vacuum . . . . . . . . . . . . . . 17

Mobility and Metabolic Cost.............. 21

Circulatory Effects. . . . . . . . . . . . . 21

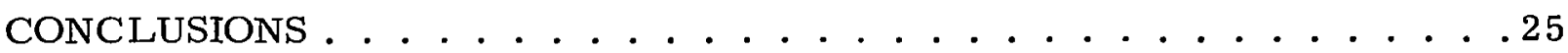

REFERENCE LIST . . . . . . . . . . . . . . 28 


\section{LIST OF FIGURES}

page no.

Figure 1. Formation of water vapor in tissue in a near vacuum . . . . . . 3

Figure 2. The double sleeve of elastic net used in vacuum chamber tests . 10

Figure 3. Arm chamber used to produce negative pressures in both ground level and altitude tests . . . . . . . . . . . . 12

Figure 4. Range of joint movement in the arm chamber . . . . . . . . .14

Figure 5. The cuff seal developed to eliminate a tourniquet effect on the arm .......................... 15

Figure 6. Plot of total pressures in the altitude chamber and the arm chamber during two exposures of the protected arm to near-vacuum conditions . . . . . . . . . . . . . . 20

Figure 7. Results of temperature measurements taken in two later altitude chamber experiments . . . . . . . . . . . . . 22

Figure 8. Axillary artery pulsatile blood flow and venous flow obtained with the Doppler flowmeter . . . . . . . . . . . . . . 24

Figure 9. Change in arm volume with exposures to increasing differential pressures for twenty minutes . . . . . . . . 26

\section{LIST OF TABLES}

Table I. Summary of SA.S experiments . . . . . . . . . . . . 18-19 


\title{
THE PRINCIPLE OF THE SPACE ACTIVITY SUIT
}

\author{
by Paul Webb, M. D. and James F. Annis \\ Webb Associates, Inc.
}

\section{SUMMARY}

There are serious penalties inherent in the limited mobility and high metabolic cost of activity in the full pressure suits used today in space. In this report we describe a different approach to the protection of a man exposed to a vacuum while he is actively working outside a space vehicle. Uniform mechanical counterpressure is applied to the limbs by an elastic net garment which permits excellent mobility at small metabolic cost, while oxygen under pressure is furnished via a helmet and breathing bladders. The period of use is limited to the one to four hours planned for extravehicular activity.

In a preliminary study to demonstrate the principle of the full Space A.ctivity Suit (SAS), we designed and constructed a hand-and-arm garment of an elastic bobbinet fabric woven for the Jobst Institute, Toledo, Ohio. Using knowledge of the properties of the fabric and calculated hoop tensions, sleeves and gloves were cut and sewn in a single piece to deliver $100 \mathrm{~mm} \mathrm{Hg}$ counterpressure in two layers.

Tests were performed in a specially constructed Lucite vacuum chamber which contained instrumentation for physiological measurements, motion study, and pressure measurement, both on the ground and in an altitude chamber. Near-vacuum exposure in the altitude chamber for 20 minutes produced no evidence of gaseous swelling; arterial and venous circulation was adequate; mobility and finger dexterity were excellent; subjective discomfort was minimal or non-existent; and increase in arm volume from accumulation of tissue fluid was limited to approximately $5 \%$ when the $100 \mathrm{~mm}$ sleeve was used at a differential pressure of $150 \mathrm{~mm} \mathrm{Hg}$.

Despite the severe limitations imposed by the unusual test configuration, we feel these preliminary tests indicate the feasibility of developing a full SAS, which would offer the advantages of increased mobility at minimal additive energy cost; simplicity of design; low risk if the suit should be torn; and, since sweat can evaporate through the porous net, physiological temperature regulation without power or cooling machinery. 


\section{INTRODUCTION}

\section{Problems of Mobility in Full Pressure Suits}

Full pressure suits used in U.S. and Soviet space flights are enclosures of gas-tight cloth, pressurized throughout with gas at 0.25 to 0.4 atmosphere. Gas bag suits are stiff cylinders except where specific joints or flexible structures are located. Many kinds of flexible members have been developed in the past thirty years to make such garments at least moderately mobile, and they have been satisfactory for emergency use in aircraft or space cabins. In contrast, space activities call for all kinds of movements. Walking, digging, climbing, stooping, and lifting are done with all the joints and flexures of the body--flexing and twisting of the vetebral column from head to pelvis; tilting of the pelvis; rotation, abduction, adduction, flexion, and extension of arms and legs; and translation of pivot points like the movable ball and socket shoulder joint. The vetebral column and the joints of the hands and wrists are flexible in several planes. To match these complex motions in a gas-filled suit is a formidable job, one which has not yet yielded to a concentrated and prolonged effort in research and development.

Symptomatic of difficulties in current suits are the related problems of awkwardness, limited mobility, and high metabolic cost for even simple activities. Restricted motion penalizes the essential jobs the astronaut should perform, and high metabolic cost means high oxygen cost, high heat production, and rapid onset of fatigue.

It is not our intent to condemn full pressure suits. They are useful operationally in military aircraft, as described by Gell et al (1). Newly developed "hard suits" promisc greater mobility and lower metabolic cost-but such suits may still be awkward and bulky compared to the ideal fulfillment of the SAS concept.

\section{Basis of the SAS Approach}

The starting point conceptually for the SA.S is that the human skin itself is an ideal pressure suit; the skin is essentially gas tight, elastic, and obviously non-restrictive to motion. The whole body may be exposed to a vacuum for brief periods of one to three minutes without any protection at all, the time limit being set primarily by hypoxia. This has been established by exposures of primates and dogs to a nearly complete vacuum, as reported by Bancroft and Dunn (2), Koestler (3), Rumbaugh and Ternes (4), and Cooke and Bancroft (5). In the laboratory, human hands have been exposed to near vacuum conditions ( $5 \mathrm{~mm} \mathrm{Hg}$ absolute pressure), with the result that swelling from evolution of gas was not evident until at least two minutes and often as long as eight to ten minutes after exposure. This is shown in Figure 1, which 


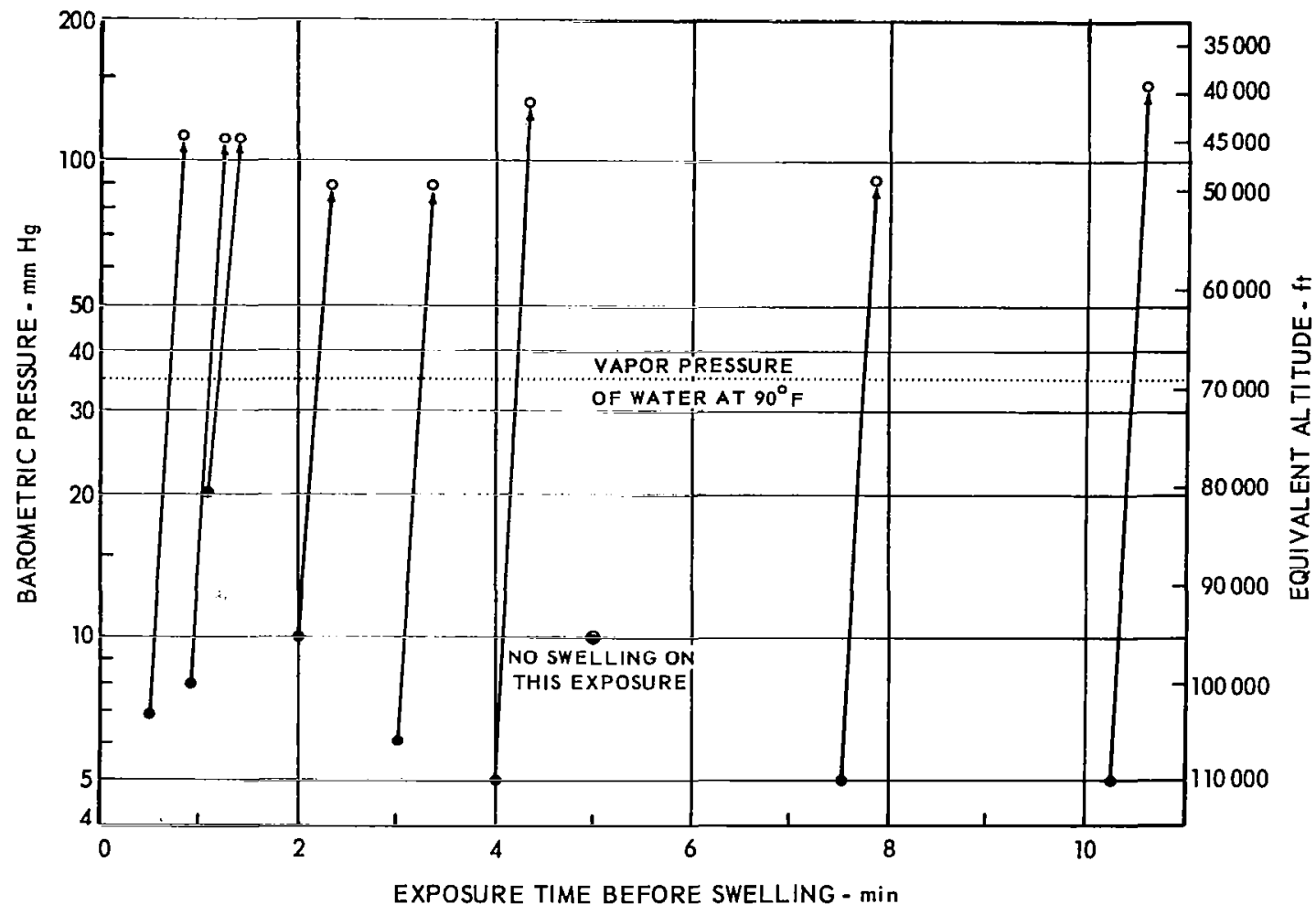

Theoretically, water vapor should appear in human tissues if the barometric pressure is less than the vapor pressure of water at the temperature of the tissues. In experiments on the unprotected human hand, illustrated above, it was found that a pressure below that equal to water vapor pressure at skin temperature was required. The discrepancy may have been due to the forces exerted by connective tissues within the hand, and the elastic nature of the skin covering.

Appearance of water vapor occurred suddenly and manifested itself by marked swelling of the hand after a variable time at altitude. After appearance of swelling, the pressure in the altitude chamber was quickly raised; the hand was examined periodically. The upper point $(O)$ represents the first point at which swelling was no longer visible to the eye. (X-ray photographs showed some residual vapor at somewhat higher pressures in a few experiments.)

If chamber pressure was again lowered slightly, swelling again appeared, indicating the continued presence of bubble nuclei in the hand tissues. This suggests that once water vapor bubbles appear, $\mathrm{O}_{2}$ and $\mathrm{CO}_{2}$ diffuse into the bubbles, which thus come to be made up of gas saturated with water vapor.

Figure 1. Formation of water vapor in tissue in a near-vacuum. Page 100 in Bioastronautics Data Book, NASA SP-3006, 1964, and drawn from data of Wilson (6). 
is data from the study of Wilson (6). There are a number of other reports of harmless swelling in hands exposed to low pressures--e. g. Ernsting et al (7), Henry et al (8), and McGuire (9). It would seem that the skin in its natural state exerts a useful degree of elastic counterpressure, and adding some mechanical pressure--100 mm Hg seems safe from Wilson's experiments-will prevent gas from forming. Wilson deduced that tissue pressure in the hands must be at least $28 \mathrm{~mm} \mathrm{Hg}$, and it may be higher.

A.s far as the skin is concerned, particularly that over the solid parts of the body, what is needed essentially is an elastic mesh, a porous restraint garment which will support the skin and prevent it from yielding to the potential distortion of gas forming in the tissues.

\section{Scope}

In this paper we describe the Space Activity Suit (SAS) as presently conceived and present the results of an experimental demonstration of the principle using an elastic glove and sleeve to protect subjects during 20minute exposures to a near-vacuum environment.

\section{SAS DESIGN PRINCIPLES}

The SAS design goal is to provide a suit which gives adequate protection in a vacuum and which has nearly complete flexibility and mobility in all the large and small motions of the body. The period of wear is limited to four hours.

The major feature of the SAS is the use of elastic fabric to cover the limbs and some part of the trunk. Powerful new elastic materials have been developed in the past ten or fifteen years, some for ladies' foundation garments, some for medical support stockings and sleeves. It is reasonable to expect to be able to apply $100 \mathrm{~mm} \mathrm{Hg}$ or more with the elastic tension of these materials. Many of the simpler joints such as those of the fingers, wrists, and elbows can move through their full ranges with little extra effort when the part is simply enclosed in elastic material.

More complex joints such as those at the hips and shoulders require special construction in addition to the elastic material and its flexibility, and for these we have devised what we call "soft joint" structures. What is needed is a kind of "tissue," to use a biological term, which maintains its volume, transmits counterpressure, and yet easily arranges itself within the fixed volume. In its simplest form, a soft joint would be a porous cloth bag filled with lubricated small, hard spheres which slide easily over each other. The bag is placed under the elastic outer garment and wrapped around the shoulder joint, for example, so as to entirely invest the shoulder to make a 
constant volume joint. The elastic pressure is distributed through the axilla and on the shoulder. As the shoulder joint moves and as the pivot point slides over the upper thorax within this soft joint, the lubricated spheres rearrange themselves, permitting mobility in all directions. The same sort of soft joint might be achieved with a shaped bag of rubberized cloth which is filled with a slippery liquid like si licone oil.

The application of a powerful elastic garment to the extremities will change the natural shapes of some parts from concave to convex by simple pressure. Other concavities may require special attention, and again the soft joint or fluid-filled bag is the answer.

The hand and foot contain rows of small bones side by side which resist being formed into a cylinder. Here special filling structures are needed to distribute the force of the elastic garment to the top and bottom instead of mostly to the sides.

A full Space Activity Suit is a complete elastic leotard with integral gloves and socks. A partial pressure helmet and full breathing bladders are part of the assembly. The lower part of the back does not contain a bladder but is heavy elastic material to allow flexion and torsion of the spine. For use in the space environment, one adds to this garment a freely permeable outer garment for protection against micrometeorites with a reflective outer coating to protect against extremes of thermal radiation. The complete assembly should allow much better mobility and much more natural movement than presently designed suits. The basic physiology of such a suit is established and the elastic materials available promise to be adequate to the task.

The advantages of the SAS approach are numerous. In addition to increased mobility and more natural movement, there is a lower metabolic cost than is exacted by full pressure suits. The simplicity of the approach is appealing; there is nothing catastrophic about tearing the elastic material. Thermoregulation is essentially free. The astronaut would have to carry only oxygen for breathing.

Of course the problem is not all this simple. In addition to preserving the basic shape of the skin over the body, three vital physiological functions must be carefully maintained. These physiological systems are, in order of priority: the mechanics of respiration, the systemic and pulmonary circulation, and thermoregulation. Let us consider each of these briefly and indicate what must be done to maintain homeostasis. 


\section{MAINTENANCE OF PHYSIOLOGICAL FUNCTIONS}

The Mechanics of Respiration

Gas must be delivered to the lungs at a pressure sufficient to insure diffusion of oxygen into the blood. A minimal design value is $150 \mathrm{~mm} \mathrm{Hg}$ when pure oxygen is breathed in a vacuum by an active man. $170 \mathrm{~mm}$ is safer, and $200 \mathrm{~mm}$ is quite conservative. $150 \mathrm{~mm}$ is equivalent to breathing air at 8000 feet. Alveolar oxygen tension is $63 \mathrm{~mm}$ and arterial saturation is about $90 \%$. In addition, there must be volume compensating counterpressure applied to the chest and abdomen in order to match the alternating volume changes of respiratory movement. Techniques for achieving this with pressurized bladders connected to the breathing supply are well established, as in partial pressure suits (Henry and Drury, 10), the RCAF vest and the RAF jerkin (Ernsting, 11). The physiology of positive pressure breathing (PPB) is understood and its problems can be managed with good helmets, breathing bladders, and regulators.

\section{The Circulatory System}

This is the next most critical function to be maintained, and the one which has caused a good deal of trouble in the development of partial pressure suits. Past experience with PPB has shown that when mechanical counterpressure is applied to the limbs there is both arterial inflow (which is aided by $\mathrm{PPB}$ ) and venous return. If tissue pressure in the limbs is less than in the trunk, the large veins of the limbs fill, thereby trapping and pooling some of the circulating blood. Also, if the limb tissue pressure does not match the intrathoracic pressure, there can be a slow filtration of fluid into the tissue, or at least a slow accumulation of tissue fluid. Applying as much as $150 \mathrm{~mm} \mathrm{Hg}$ mechanical pressure with an elastic garment significantly reduces both pooling and fluid accumulation, but it may not be necessary, since the wearer of an SAS will be active and the changes in tissue pressure occuring with muscular activity will considerably aid venous return and possibly reduce fluid filtration or blockage of lymphatic drainage, whichever is involved here. For a four-hour period full of physical activity, it seems probable that the limbs will receive sufficient circulation and will not swell significantly if the elastic garment delivers 100-125 $\mathrm{mm} \mathrm{Hg}$ of mechanical pressure.

\section{Thermoregulation}

In a space suit, thermoregulation is a problem of heat dissipation. An astronaut outside the vehicle must be protected from extremes of the thermal radiant environment, and this is nicely accomplished in present suit design by reflective coatings which virtually isolate the man thermally. There is no conductive or convective exchange in a vacuum. Since the man is constantly 
producing heat, and since the heat production will be sizable and variable if he is to carry out useful activities, heat dissipation should be rapidly variable and matched to the requirement of maintaining thermal balance.

Fortunately, physiological control of heat dissipation by evaporation of sweat is a major mechanism of the body which provides precise regulation. The porous net of an SA.S permits instantaneous evaporation of any water which comes through the skin. The steady diffusional water loss (insensible perspiration) in a vacuum amounts to about 100 grams of water lost per hour, as estimated by extrapolation from the data of Hale et al (12) and from some preliminary experiments of Webb et al (13). This represents a heat loss of $56 \mathrm{kcal} / \mathrm{hr}$, which is roughly half the metabolic heat production of a man standing at rest. If there is any additional water produced on the skin, either from psychogenic sweating or thermal sweating, it will be instantly evaporated and cooling will take place at the rate of $0.56 \mathrm{kcal} / \mathrm{gm}$ of water lost. It is only necessary to provide a free pathway for the escape of these water vapor molecules through any outer protective layers of a garment assembly. Not only is this evaporative cooling route constantly available and under full control by the body, but also it requires no additional machinery or power. The limit, of course, would be dehydration of the astronaut. If his work load were maintained at a steady $300 \mathrm{kcal} / \mathrm{hr}(1200 \mathrm{Btu} / \mathrm{hr})$ for four hours, the total loss of water would be just over 2100 grams, or 4.7 pounds for the whole period. It all evaporates and cools; there is no need for the body to secrete two or three times the sweat required for cooling, as is often true in an air environment on Earth.

\section{POSITIVE PRESSURE BREATHING WITH MECHANICAL PRESSURE}

Historically, full pressure suits consisting of rubberized canvas pressurized with gas were the first devices tried to enable man to fly higher than 40,000 feet. Wiley Post in America and Squadron Leader Swain in England flew with full pressure suits in the early 1930's. These early suits were awkward, hot, difficult to put on and take off, and virtually immobile. During World War II, when military aircraft were designed to fly above 40,000 feet, the physiology of positive pressure breathing (PPB) was exploited. Gagge et al (14) described early research in PPB, which was followed by operational use of $15 \mathrm{~mm}$ of positive pressure for altitudes up to 45, 000 feet. At higher positive pressures there was difficulty in breathing, discomfort in the head and neck, and danger of circulatory collapse. The addition of breathing bladders over the chest, as in the RCAF and RAF vests, permitted breathing up to $30 \mathrm{~mm} \mathrm{Hg}$ pressure for significantly long periods from an oxygen mask; however, there was still discomfort in the face and neck. Full helmets were then added to relieve this discomfort, but now the problem became one of circulatory collapse from raised intrapulmonary pressure because of the marked reduction in venous return to the heart. 
A helmet and a full trunk bladder extending down over the upper thighs--the RAF jerkin--permitted higher breathing pressures for protection in higher altitudes, but for short periods. It was found that for exposures beyond a few minutes it was essential to add bladders to the legs and then bladders to the arms, which brought on restriction of mobility. The history of this development and the physiology of PPB are nicely reviewed in the monograph by Ernsting (11).

By 1946 the American research in PPB and mechanical pressure culminated in the partial pressure suit introduced by Henry and Drury (10). Added to trunk bladders and helmets were gas-filled tubes running down the arms and legs, which were tied to the suit material with tapes. When these capstan tubes were inflated, the inelastic and tightly fitted cloth of the arms and legs was drawn up tight, thereby applying mechanical pressure to the limbs. An evaluation of the suit was reported by Jacobs and Karstens (15). The suit was intended to give protection against decompression in high altitude aircraft, allowing time to bring the craft down to safe altitudes. For such short periods, nearly complete coverage of the trunk with breathing bladders proved useful, but these bladders plus the anti-G suit bladders on the legs made the pilot hot, since perspiration could not evaporate. The full bladders were used in a later suit by McGuire (9). Temperature regulation continued to be a severe problem, since more than $50 \%$ of the skin was covered by impermeable layers. The suit was useful in aircraft operating at very high altitudes (Wilson, 16), and it had been tested in a chamber to 198, 000 feet (McGuire, 9), but it was never intended to be used by an active man in a space vacuum.

Another suit using the partial pressure suit principle is the "passively pressurizing partial pressure suit" described by Davis et al (17). An inelastic outer garment covers gas-filled blind tubes running over the limbs and trunk, tubes which expand as the pressure in the aircraft cabin goes down. A partial pressure suit helmet and regulator are used. Volume compensation for breathing is achieved by taking advantage of the large volume available in the expanded tubes running from extremities to trunk.

None of these suits employing PPB and mechanical counterpressure to the limbs was designed particularly for mobility nor for intentional operation in a full vacuum.

\section{EXPERIMENTAL DEMONSTRATION OF PRINCIPLE}

To demonstrate the principle of the Space Activity Suit, we have used a powerful elastic material to make a complete glove and sleeve for one arm. This arm assembly has been tested at ground level and during altitude chamber simulations of the vacuum of space. An arm so protected has been exposed to a total pressure of less than $8 \mathrm{~mm} \mathrm{Hg}$ (a $99.3 \%$ complete vacuum) for 20 minutes without apparent damage and with good mobility. 


\section{Method of Sleeve Construction}

Choice of material. -- We studied various elastic knitted and woven materials in order to find one with sufficient power to increase the pressure of the arm tissue by approximately $100 \mathrm{~mm} \mathrm{Hg}$. The power developed by fabrics constructed of elastic fibers, whether natural or synthetic, is a function of both the fiber size and the method of knitting or weaving. Power net materials for foundation garments are usually made by the Raschel knit process; knitted materials stretch well in all directions. Woven materials can be made with either one-way or two-way stretch. The material chosen for the final tests was a special fabric (bobbinet) woven for the Jobst Institute of Toledo, Ohio, with cotton-covered rubber strands in the warp direction and 100 denier nylon in the fill. The material stretches in both directions, but farther and with more power in the warp. The sleeves were cut with the warp running circumferentially around the arm.

Another important specification was that the material could be used in a vacuum without losing its elasticity. Natural rubber fibers meet this requirement, and so do some of the butadiene synthetic rubbers and at least one brand of spandex polyurethane elastomer. After obtaining samples of many elastic materials with various properties, we put some of the more promising into a vacuum dessicator jar, which was kept evacuated to a pressure of less than $1 \mathrm{~mm} \mathrm{Hg}$ for 24 and 48 hour's. Neither the rubber not spandex fibers of the better materials deteriorated after 48 hours exposure.

Pattern making:- - In order to achieve the desired high pressure from the elastic garment we developed patterns according to dimensions taken from the arms of two subjects. Each arm was carefully measured as to length and circumference, with the circumferences being taken every $1-1 / 2$ inches. These dimensions were then reduced arithmetically to make a pattern. When a garment was sewn to this pattern with materials of known elastic characteristics, the power of the garment when donned could be predicted from the reduction in dimensions used. For example, if a one-inch length of material is stretched to 1-1/2 inches, or $50 \%$ elongation, the force required to achieve the stretch may be, for example, two pounds. By computing the hoop tensions required for each circumference to achieve the desired $100 \mathrm{~mm} \mathrm{Hg}$ pressure, the amount of stretch at each point could be specified.

Sewing.--After experimenting with a number of different methods of stitching and seaming, we settled on a flatlock seam the full length of the sleeve with termination of the sleeve around the base of the thumb and the bases of the fingers. The thumb form required two longitudinal seams, while the fingers required single longitudinal seams up the back. The flatlock stitch was useful in that it was strong and held the cut ends of the elastic fibers and prevented them from withdrawing as they were stretched. Figure 2 is a photograph of a complete sleeve made in this fashion. Alongside it is 
a second oversleeve which does not contain fingers. The two sleeves together developed approximately $100 \mathrm{~mm} \mathrm{Hg}$ pressure by computation. The fingers did not need a second layer, we found. We made double sleeves to fit the left arms and hands of the two experimental subjects.

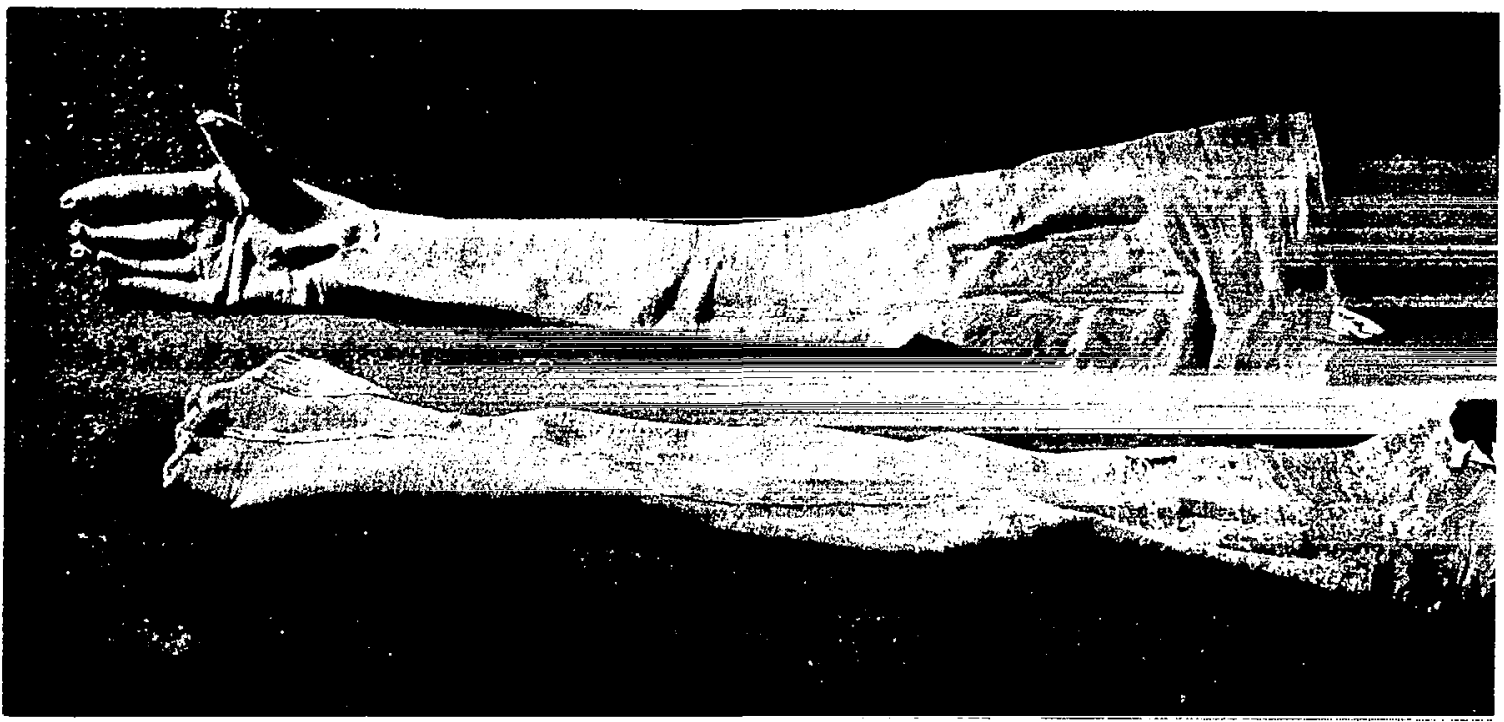

Figure 2. The double sleeve of elastic net used in vacuum chamber tests. The upper arm portions flare out from mid-biceps in order to reduce the elastic pressure to zero at the top of the sleeve. Sticky caulking compound is visible in this same region.

Soft joints and special fills.--We explored the soft joint concept in a preliminary way. First we made a kind of bean bag shaped to surround the elbow with extensions and greater depth for the fossae on each side of the olecranon process. The bag was made of light porous cotton fabric and underfilled with approximately $100 \mathrm{ml}$ of $1 / 8^{\prime \prime}$ smooth Lucite spheres. When put in place around the elbow joint and covered with an elastic sleeve, the spheres filled the fossae properly during elbow extension, then rearranged 
themselves as expected when the elbow was flexed. Later we found a simpler way of filling these fossae. A thin-walled rubber tube was underfilled with silicone oil (Dow Corning 360 Medical Fluid), cut to fit the cavity, evacuated and sealed. This lay under the elastic sleeve and was internally slippery enough to form and deform readily with joint motion while maintaining a convex outer surface at all times. Since we found, however, that the elbow and wrist joints did not actually require special structures to achieve full flexion, extension, or rotation, we did not work further on soft joints.

A problem appeared when we began to use gloves made of the powerful bobbinet material. The circumferential force at the hand, where the four metacarpals lie side by side, applied itself principally to the edges of the hand, only slightly to the back, and not at all to the concave palmar surface. Therefore we made molded silicone rubber pads to fit the palm and back of the hand for each subject. Worn under the elastic glove, the pads rounded out both surfaces and distributed the force more uniformly. Before these pads were used we had observed during exposures of the arm to negative pressures of 150 and $200 \mathrm{~mm} \mathrm{Hg}$ that petechiae formed readily over the back of the hand--but oddly enough there was never damage or discomfort on the palm, despite the fact that the elastic material bridged across without contacting the skin. Palmar skin is thicker and tougher than that on the dorsum, and it may be attached more securely to underlying structures.

There are other hollow places at the wrist and volar surface of the elbow, but special fills were not needed. The rounding force of the elastic sleeve was apparently great enough so that adjacent soft tissue filled these small hollows.

Subjectively, the sleeves felt comfortable when donned. There was no pinching or sense of force unevenly applied. When the protected arm was subjected to negative pressure in the arm chamber, there was little sensation of pressure--and none of vacuum--and motions were quite free.

\section{Arm Chamber}

To conduct the experiments, we constructed an arm chamber of $1 / 2^{\prime \prime}$ Lucite in the shape of a cylinder $18^{\prime \prime}$ in diameter and $36^{\prime \prime}$ long. One end plate for the cylinder fitted against a shoulder stop with an O-ring seal. It could be easily removed to allow access to instrumentation inside. The opposite end was covered with a fixed Lucite plate which contained a 7-1/2" armhole with a reinforced beveled edge to mate with the arm sealing device. Figure 3 is a sketch and photograph of the arm chamber. 


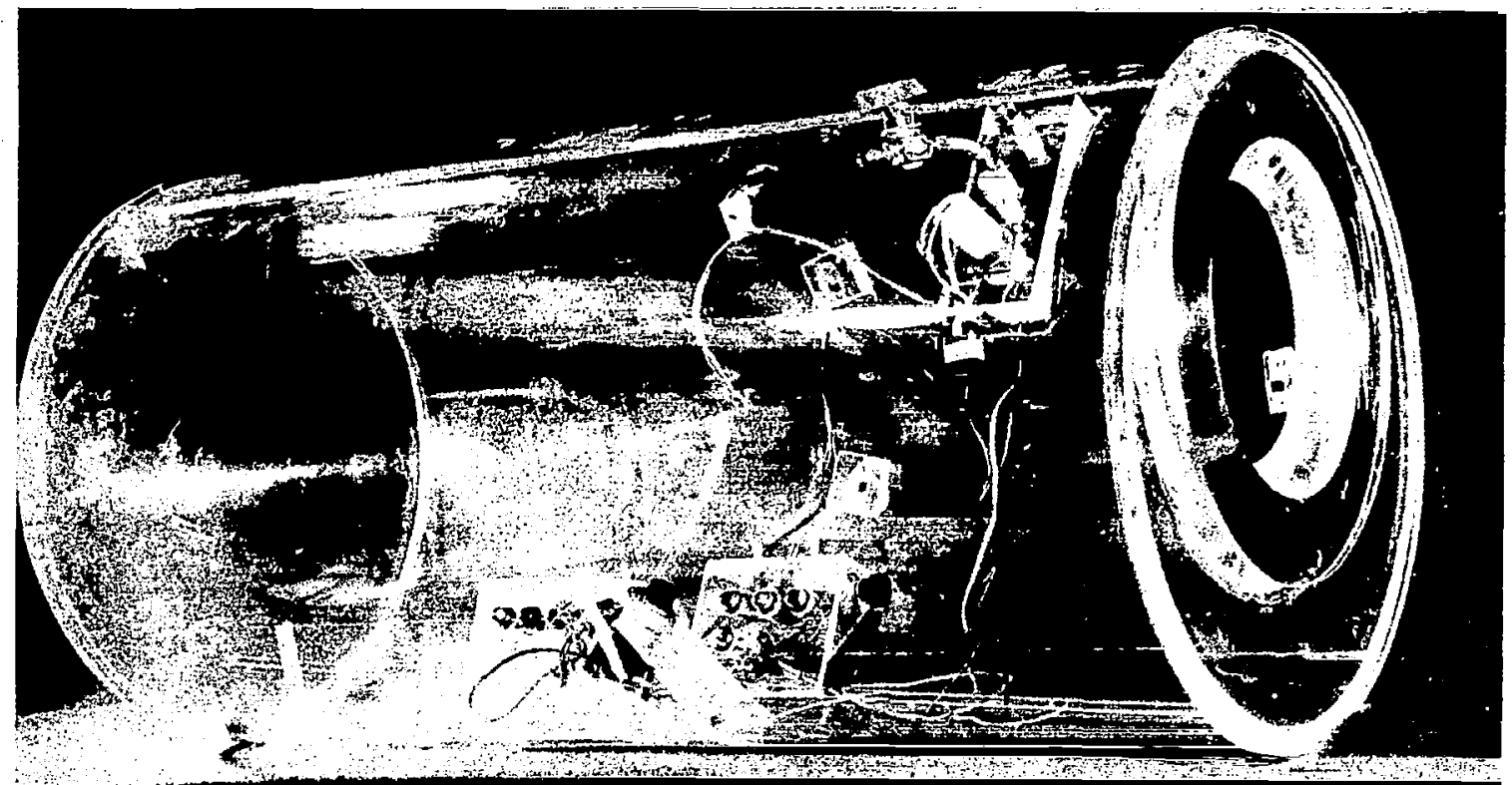

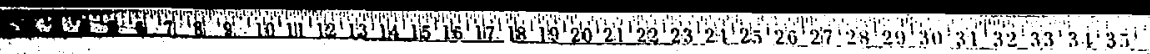
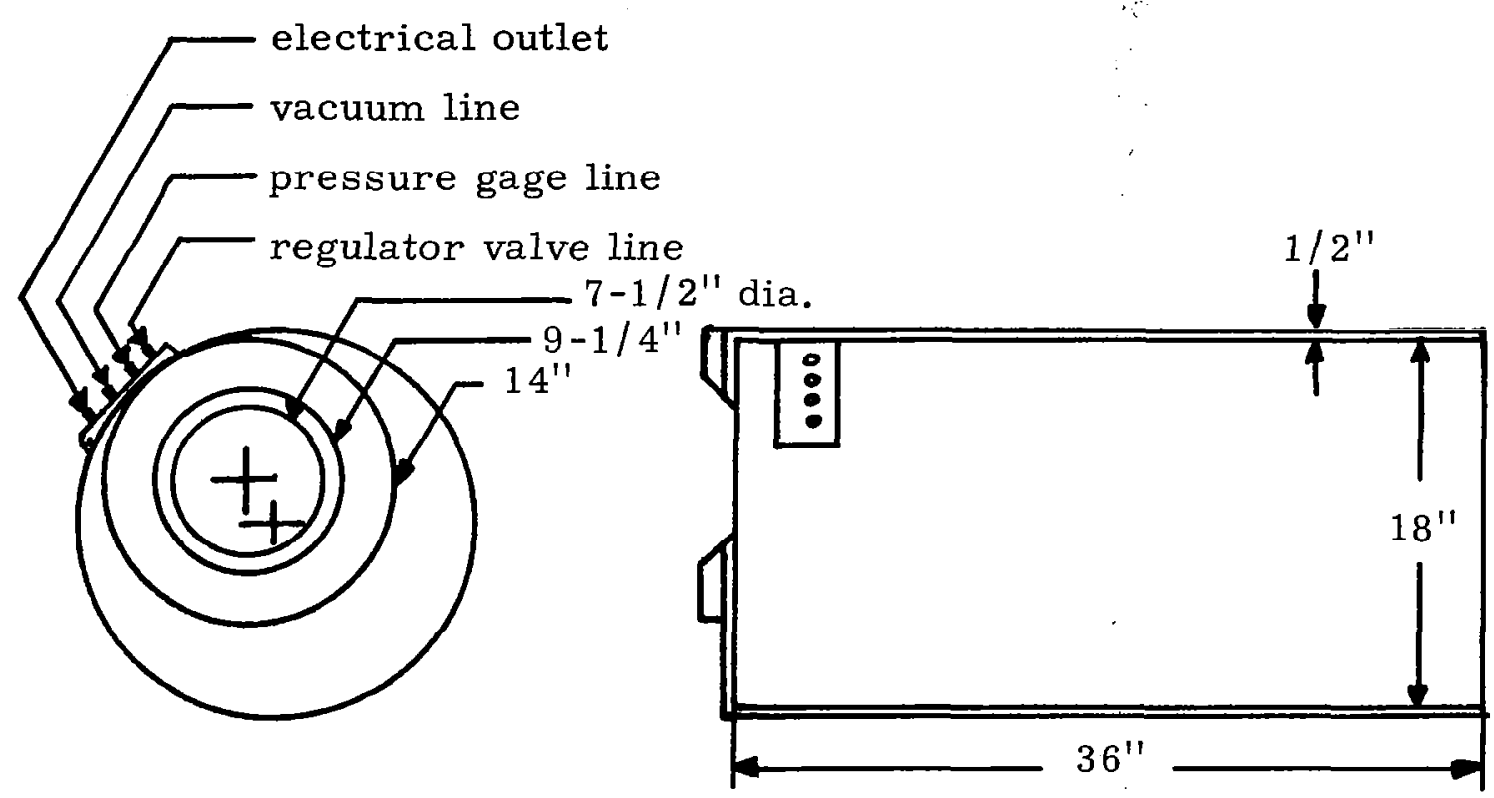

Figure 3. Arm chamber used to produce negative pressures in both ground level and altitude tests. 
The arm chamber was fitted out in the interior with a number of electrical switches, knobs, and colored lights. The subject, whose arm was inserted to the shoulder, could easily move his arm inside the chamber, bending his elbow and wrist and manipulating switches and dials with his hand.

Figure 4 gives the average movements required to operate these controls and the maximum movements possible in the arm chamber. These movements are compared with the comparable maximum unimpeded joint range given by Barter (18). The arm chamber measurements were obtained in place using protractors and a goniometer. Care was taken to limit movements in the fixed member reference during the measurements. Any loss in movement of the fingers associated with wearing the garment was undetectable, i. e. a complete fist could be made. Complex motions were recorded on motion picture film while wearing the sleeve.

Sealing the arm to the armhole was something of a problem. Experiments involved evacuating the arm chamber until its pressure was 150 or 200 $\mathrm{mm}$ less than the ambient pressure. This meant that the arm had to seal to the beveled edge, and that there should be as little restriction as possible to the circulation in the arm other than that caused by the pressure differential. The final solution was as follows: after the elastic double sleeve was pulled on, a rigid plastic cuff about $3^{\prime \prime}$ wide was slipped up to the top of the sleeve and the small gap between the sleeve and rigid cuff filled with a sticky caulking compound. A heavy rubber cuff was pulled up over the rigid arm cuff and clamped with a hose clamp. The rubber cuff was already attached and sealed to a metal ring and Lucite plate which matched the beveled edge of the armhole in the chamber. The gas seals proved satisfactory, since the sticky caulking compound filled the porous elastic material under the rigid cuff and the rubber sealed readily to the plastic cuff from the outside. At the same time there was no particular discomfort and no tourniquet effect from this arrangement. Figure 5 is a photograph and sketch of the sealing cuff arrangement.

\section{TESTS}

The object of the testing was to see what happened to the arm when the subject was at one pressure and the arm at the nominal differential pressure of $150 \mathrm{~mm} \mathrm{Hg}$, the condition which would obtain in the full SAS suit with 150 $\mathrm{mm} \mathrm{Hg}$ in the helmet and breathing bladder. We conducted experiments at ground level with the subject comfortably seated in a room, his arm sealed into the arm chamber, and evacuation done with a laboratory vacuum pump to a negative pressure in the chamber of $50,100,150$, and $200 \mathrm{~mm} \mathrm{Hg}$ (approximately $1,2,3$, and $4 \mathrm{psi}$, or $2,4,6$, and 8 " $\mathrm{Hg}$ ). In addition, in order to show that the arm was suitably protected under vacuum conditions, we did final experiments in an altitude chamber where the total pressure was reduced 


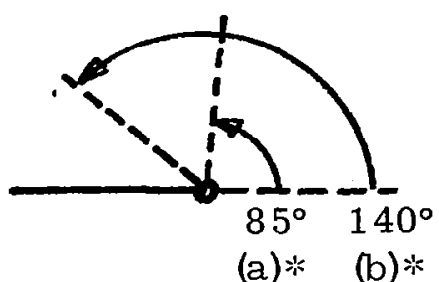

(a) $*$ (b) $*$

Elbow flexion

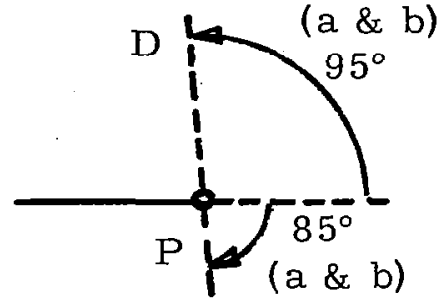

Wrist dorsiflexion (D) and palmar flexion $(P)$

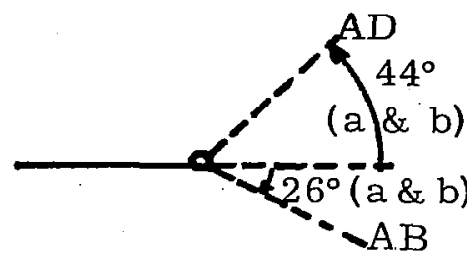

Wrist adduction (AD) and abduction $(A B)$

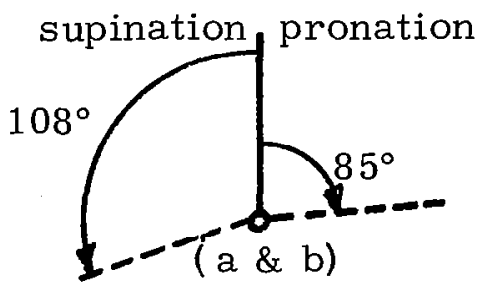

Forearm rotation

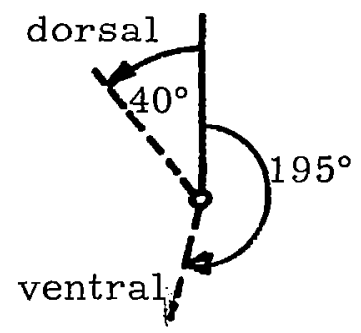

Extended whole arm rotation

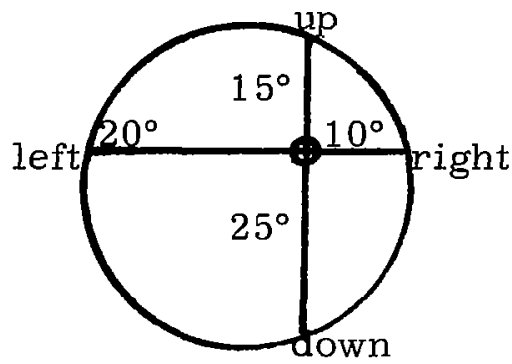

Quadrant angles and extended arm circumflexion

*(a) movement required to operate switches

*(b) maximum movement possible in the arm chamber

\begin{tabular}{|c|c|c|}
\hline Movement & $\begin{array}{l}\text { Maximum unimpeded } \\
\text { joint movement } \\
\text { (from Barter, 18) }\end{array}$ & $\begin{array}{c}\text { Maximum joint movement } \\
\text { achieved in the arm } \\
\text { chamber }\end{array}$ \\
\hline Elbow flexion & $142^{\circ} \pm 10$ & $140^{\circ}$ \\
\hline dorsiflexion & $90^{\circ} \pm 12$ & $85^{\circ}$ \\
\hline Wrist palmar flexion & $99^{\circ} \pm 13$ & $95^{\circ}$ \\
\hline Wrist adduction & $47^{\circ} \pm 7$ & $44^{\circ}$ \\
\hline Wrist abduction & $27^{\circ} \pm 9$ & $26^{\circ}$ \\
\hline $\begin{array}{ll}\text { forearm } & \text { supination } \\
\text { rotation } & \text { pronation }\end{array}$ & $\begin{array}{r}113^{\circ} \pm 22 \\
77^{\circ} \pm 24\end{array}$ & $\begin{array}{r}108^{\circ} \\
84^{\circ}\end{array}$ \\
\hline $\begin{array}{ll}\text { whole arm } & \text { anterior } \\
\text { rotation } & \text { posterior }\end{array}$ & -- & $\begin{array}{r}45^{\circ} \\
190^{\circ}\end{array}$ \\
\hline
\end{tabular}

Figure 4. Range of Joint Movement in the Arm Chamber 

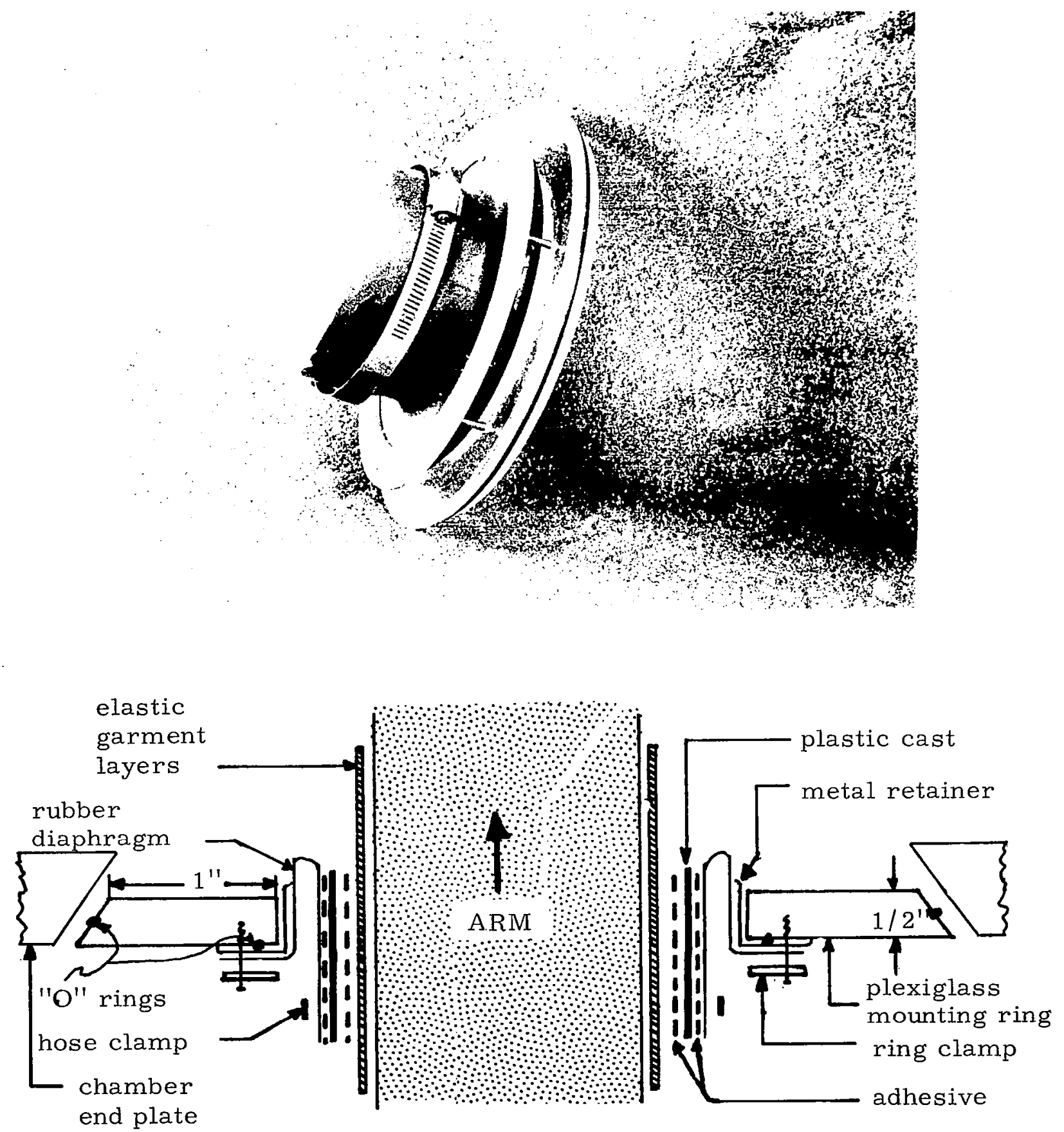

Figure 5. The cuff seal developed to eliminate a tourniquet effect on the arm. At the left of the photograph (and downwards in the diagram) is the light-colored plastic cast material; the dark material is the rubber diaphragm or cuff, clamped to the plastic cuff. The Lucite plate with beveled edge matches the beveled ring of the armhole in the arm chamber. 
to $155 \mathrm{~mm} \mathrm{Hg}$ (equivalent to $100,000 \mathrm{ft}$ altitude) or lower. The differential pressure was approximately the same, $150 \mathrm{~mm} \mathrm{Hg}$, and the arm was exposed to near vacuum conditions. More than $99 \%$ of the normal pressure at 1 atmosphere was removed from the arm chamber. Because of the need for an arm seal, these tests are likely more stringent and the results conservative compared to tests which might be made with a full suit.

The individual tests completed are shown in Table I, pp. 18-19.

The subject tested mobility and flexibility of the arm by manipulating the knobs and switches in the arm chamber, which were closely spaced and arranged over the full range of reach for an unprotected arm. The subject also assembled standard threaded connectors such as Swagelock fittings, wrote on a tablet, picked up small parts, and made similar discriminatory movements. The metabolic cost of such movements, both with and without the protective sleeve, was estimated from his pulse rates during a standardized series of movements.

To assess the state of circulation while the subject was at one pressure and the arm at a lower pressure in the arm chamber, we made several measurements. One was the temperature of the skin of the protected arm, in the expectation that if circulation were decreased the skin temperature would fall. The subject was expected to report any discomfort or pain from reduced circulation and tissue hypoxia. Inspection of the skin would show petechiae as evidence of surface damage.

Unusually high pressure at the venous end of the capillaries was expected to cause filtration of fluid through the capillary wall. The accumulation of tissue fluid could be accurately assessed by measuring the volume of the exposed arm before and after exposure. This we accomplished by using a long narrow metal cylinder which was completely filled with water; the subject then inserted his arm to a measured depth and the overflow of water was caught and weighed. This measurement was generally made within two minutes after repressurization and sleeve removal. The weight of the water was related to arm volume, and any change in arm volume was reflected in a change in weight.

Finally, the most direct but most difficult measurement of circulation is a measurement of blood flow, and we attempted this qualitatively with an ultrasonic flowmeter (Doptone; Smith Kline Instrument Co., Philadelphia, Pa.). The sensing head was applied to the brachial vein and to the artery where they come into the axilla. Arterial flow is detected audibly with a loudspeaker or visually on an oscilloscope as a characteristic alternating pattern. Under normal circumstances (no differential pressure or elastic sleeve) venous flow is audible or visible as a continuous signal which increases when the subject 
is asked to make a fist. We were able to detect not only arterial inflow but venous outflow when the muscles were tensed under all conditions tested except the negative pressure of $200 \mathrm{~mm} \mathrm{Hg}$, when venous flow was absent.

\section{RESULTS}

The results will be discussed in the following order: the effect of vacuum; mobility and metabolic cost; and circulatory effects.

\section{Effect of Vacuum}

The effect of exposure of the protected arm to a vacuum, i. e. less than $1 \%$ of 1 atmosphere pressure, was essentially nil. As expected, the double sleeve prevented any visible swelling from the formation of gas bubbles in the hand or arm. Exposure to a vacuum produced no discomfort and no change in mobility or flexibility. The exposed hand and arm felt cool subjectively and skin temperatures were lower, as described below. The subjective sensations and experimental measurements in the vacuum experiments at altitude were the same as those at ground level when we tested at the same differential pressure.

Figure 6 shows graphically a time history of two 20-minute exposures to low pressure in the arm chamber. In one case the pressure reached in the arm chamber was $13 \mathrm{~mm} \mathrm{Hg}$ absolute, in the other the lowest pressure reached was $5 \mathrm{~mm} \mathrm{Hg}$, and the period of time below $8 \mathrm{~mm} \mathrm{Hg}$ was just over 19 minutes. The altitude chamber was maintained at 38,000 ft equivalent \pm 1000 feet, and the differential pressure was between 130 and $155 \mathrm{~mm} \mathrm{Hg}$ in both exposures.

Two earlier altitude chamber tests were conducted with higher differential pressures but also with higher absolute pressures in the arm chamber. These tests were done before the final arm seal was perfected. In one of these the absolute pressure in the arm chamber was $24 \mathrm{~mm} \mathrm{Hg}$ when the altitude chamber was at $200 \mathrm{~mm} \mathrm{Hg}$, giving a differential pressure of $176 \mathrm{~mm}$ $\mathrm{Hg}$. This exposure lasted only a few minutes and was terminated due to difficulty with equipment. In the other test there was an exposure time of 27.5 minutes in which the arm was exposed to an absolute pressure of $50 \mathrm{~mm}$ $\mathrm{Hg}$ on the average. The differential pressure ranged from 150 to $200 \mathrm{~mm} \mathrm{Hg}$. In both of these altitude experiments with higher differential pressures the subjects did not complain of ischemic pain and there was no visible evidence of damage. In the longer exposure there was arm swelling afterward, with an increase in arm volume of nearly $200 \mathrm{cc}$ or $8 \%$ of initial value. Some of this swelling may have been produced by the tourniquet effect of the early arm seal. 


\begin{tabular}{|c|c|c|}
\hline Test & Subject & Configuration \\
\hline \multicolumn{3}{|c|}{ Grónd Level--preliminary tests: } \\
\hline 1 & A. & Bare arm--control \\
\hline 2 & B & Bare arm--control \\
\hline 3 & A & $\begin{array}{l}\text { Single layer power net sleeve; approx. } \\
50 \mathrm{~mm} \mathrm{Hg} \text { counterpressure. }\end{array}$ \\
\hline 4 & A & $\begin{array}{l}\text { Triple layer power net sleeve designed to } \\
\text { deliver approx. } 100 \mathrm{~mm} \mathrm{Hg} \text { counterpressure. }\end{array}$ \\
\hline \multicolumn{3}{|c|}{ Ground Level Tests: } \\
\hline $5 \& 5^{\prime}$ & A \& B & $\begin{array}{l}\text { Jobst two-layer bobbinet garment with fillers; } \\
\text { approx. } 100 \mathrm{~mm} \mathrm{Hg} \text {; inverted cuff seal. }\end{array}$ \\
\hline $6 \& 6^{\prime}$ & A. \& B & Same as above. \\
\hline $7 \& 7$ & A. \& B & Same as above, except no fillers for subj. B. \\
\hline 8 & A & Same as above, with semi-liquid floating seal. \\
\hline \multicolumn{3}{|c|}{ Altitude Chamber Tests--preliminary: } \\
\hline 9 & A. & Jobst garment; fillers; inverted cuff seal. \\
\hline 10 & A & Same as above. \\
\hline 11 & B & Same as above. \\
\hline \multicolumn{3}{|c|}{ Altitude Chamber Tests--later: } \\
\hline 12 & A. & $\begin{array}{l}\text { Jobst garment; semi-liquid floating seal; } \\
\text { back of hand filler only. }\end{array}$ \\
\hline 13 & B & Same as above. \\
\hline 14 & B & is above. \\
\hline
\end{tabular}


Exposure Conditions

$\begin{array}{ccc}\frac{\text { Time }}{\text { min. }} & \frac{\Delta \mathrm{P}}{\mathrm{mmHg}} & \frac{\text { Ambient P }}{\mathrm{mmHg}} \\ 2 & 150 & 750\end{array}$

5 (total) $\quad 0-175 \quad 750$

$1175 \quad 750$

$12 \quad 0-150 \quad 750$

$20 \quad 140 \quad 750$

$\begin{array}{lll}20 & 50 & 750\end{array}$

$15 \quad 100 \quad 750$

$12 \quad 150$

750

$10 \quad 200$

750

155

$27.5 \quad 100-150 \quad 150-200$

14

$150-175$

$175-250$

20

$130-150$

$140-160$

155

$-\cdots \quad-\cdots$

21

150
Comments

Ischemic pain, tourniquet sensation at $\Delta P$ of $100 \mathrm{~mm} \mathrm{Hg}$; little visible damage.

Multiple petechiae, especially on upper arm; some swelling.

Few petechiae at chamber arm seal; ischemic pain lessened by movement.

Minimal swelling and discomfort; petechiae near arm seal.

No discomfort or damage; no change in arm volume.

Minimal discomfort; no damage; volume increase approx. $1 \%$.

Little discomfort; no damage; volume increase approx. $5 \%$.

Pain increasing over exposure period; HR reached 115 BPM; $7.5 \%$ increase in arm volume; petechiae near seal.

Aborted; difficulty in sealing arm chamber.

Petechiae and ischemic pain; increase in arm volume $8 \%$.

Petechiae upper arm; volume increase $3 \%$.

No visible damage; volume increase $5.4 \%$.

Experiment terminated when altitude chamber observer developed bends.

No visible damage; no pain or discomfort; arm volume increase $5.6 \%(127 \mathrm{cc})$. 


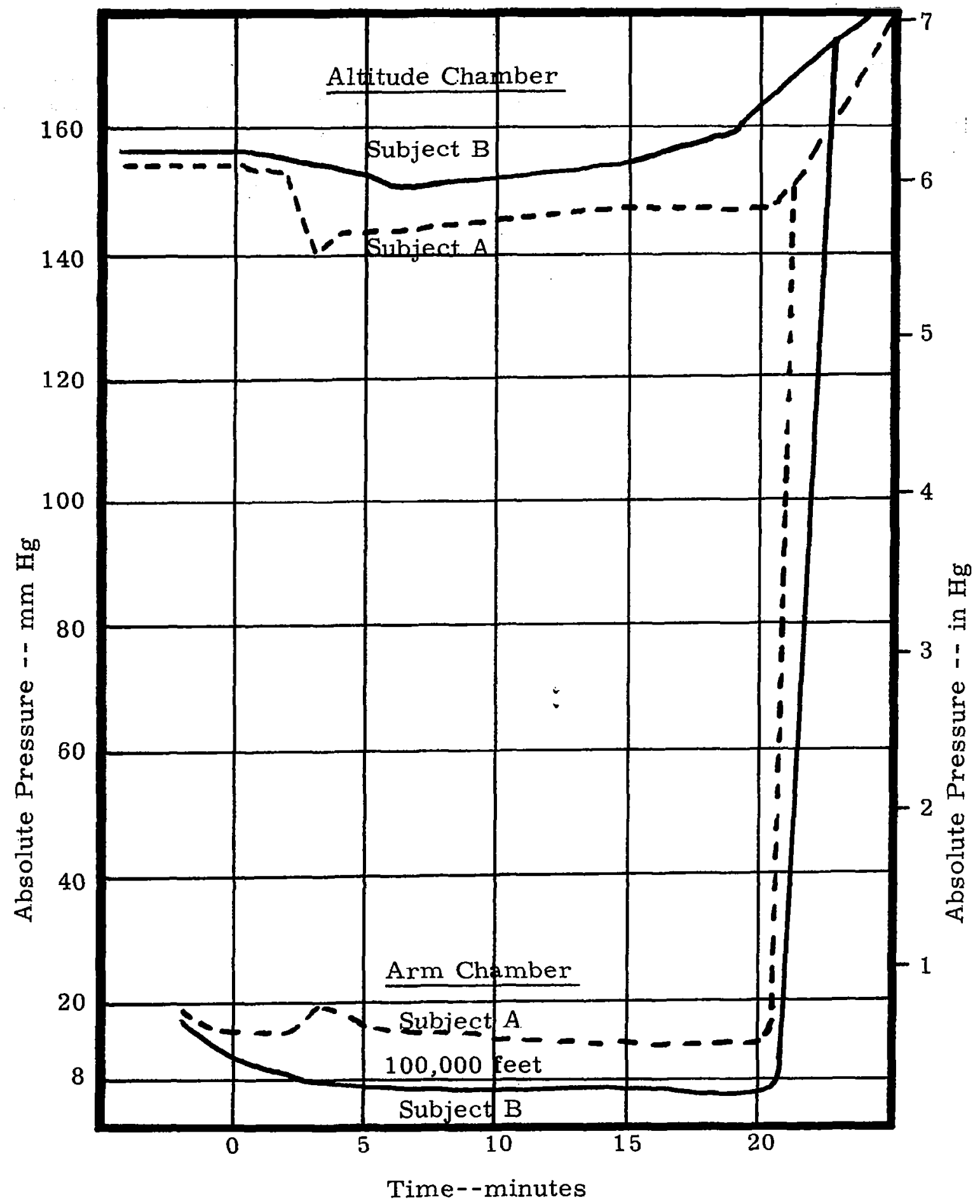

Figure 6. Plot of total pressures in the altitude chamber and the arm chamber during two exposures of the protected arm to near-vacuum conditions. Experiments 12 and 14, Table I. 


\section{Mobility and Metabolic Cost}

Mobility, dexterity, and flexibility of the protected arm and hand were excellent during both the ground level and altitude tests. The subject was able to flex his elbow and to rotate and flex the wrist freely. The fingers could be clenched into a fist and the thumb tip could be touched to each of the four finger tips. The subject had no trouble in manipulating toggle switches, slide switches, rotating potentiometers, and rotating switches.

To indicate the metabolic cost of moving in the elastic sleeve, we devised a simple 2-minute routine of exaggerated arm movements and manipulating instrument controls, and took the cost in heart rate as the index of effort. Both routines were started at the same heart rate (72 BPM) and care was taken not to induce increases due to test anxiety or other psychogenic stimuli. The routine in the control experiment produced no increase in pulse rate; neither did the routine in the elastic sleeve. Since the pulse rate is a more sensitive indicator of metabolic cost than oxygen uptake or $\mathrm{CO}_{2}$ production, we carried the investigation no further. Longer and more complex routines did not seem warranted.

\section{Circulatory Effects}

We assessed circulation in the arm four different ways (see page 16), and the results were identical for the same differential pressures at ground level and at altitude. Circulatory effects were dependent entirely upon the differential pressure between the ambient and the arm chamber.

Skin temperature in the protected hand was reduced simply by putting on the glove and sleeve. At ground level with differential pressures from 50 to $200 \mathrm{~mm} \mathrm{Hg}$, skin temperatures did not change more than 1 or $2^{\circ} \mathrm{C}$ in preliminary testing. In the altitude chamber tests with a vacuum in the arm chamber, skin temperature on the fifth digit was as much as $7^{\circ} \mathrm{C}$ lower than the comparable control finger and $2^{\circ}$ to $5^{\circ} \mathrm{C}$ below its immediate environmental temperature. Figure 7 shows typical temperature data taken during the same experiments whose pressure profiles are shown in Figure 6. We interpret this as meaning increased cooling due to improved evaporation from the hand in the vacuum. The subject was busy and the altitude chamber was warm, so that he was sweating mildly. This is confirmation of the good thermoregulatory potential of the SAS.

Gross evidence of circulatory insufficiency came at high negative pressure and insufficient tissue pressure, when the subject reported ischemic pain or we observed petechiae, small hemorrhages under the skin. We did control experiments in the arm chamber with no sleeve to protect the exposed arm. Using a rubber doughnut seal, which worsened the situation because of the tourniquet effect, both subjects observed pain developing in the arm as the 
Figure 7. Results of Temperature Measurements Taken in Two Later Altitude Chamber Experiments
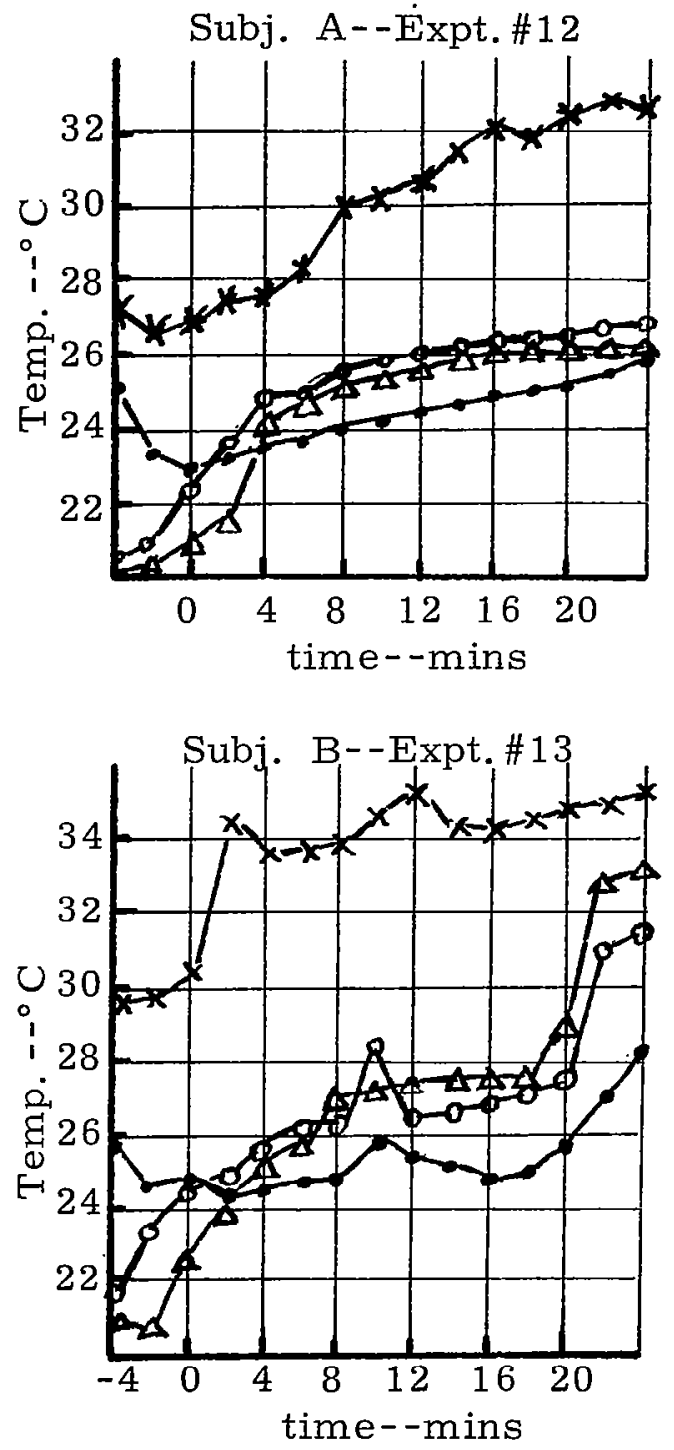

Legend:

control finger-- $\mathrm{x}$

A.rm Chamber--o

altitude chamber- $-\Delta$

test finger--

These graphs show the exposed test fingers to be the coolest of all temperatures measured. The reduced test finger temperature can be largely credited to evaporative cooling rather than to reduced blood flow, since, without any blood flow, the skin temperature could not go below its immediate environment (arm chamber) temperature. 
differential pressure increased to approximately $60 \mathrm{~mm} \mathrm{Hg}$. The pain worsened as the differential pressure was increased, and these exposures were limited to two or three minutes. The maximum differential pressure experienced without protection was $175 \mathrm{~mm} \mathrm{Hg}$ for just over a minute. This produced not only strong ischemic pain but numerous petechiae over the entire arm, especially the upper arm near the arm seal. Some petechiae were observed on the back of the hand but the fingers and palm were free of them. Muscular aching persisted for eight hours following the more extreme of these exposures. Petechiae under the skin disappeared in about two days.

In ground level testing with the protective sleeve, differential pressures of $50,100,150$, and $200 \mathrm{~mm} \mathrm{Hg}$ were used for periods up to 20 and 30 minutes. With the final sleeve, which was designed to produce $100 \mathrm{~mm} \mathrm{Hg}$ of tissue pressure, an exposure to $200 \mathrm{~mm} \mathrm{Hg}$ differential pressure for ten minutes produced muscular aching which we assigned to ischemic pain. No petechiae were formed, however, except in a few experiments where the arm seal did not fit properly, or there was a pinch of the material, or at the arm seal. In the altitude tests ischemic pain and petechiae were absent. There was mild discomfort in one exposure to an absolute pressure of $50 \mathrm{~mm} \mathrm{Hg}$ and a differential pressure of 150 to $200 \mathrm{~mm} \mathrm{Hg}$, a discomfort which was relieved by flexing the arm and making a fist periodically. Records from three different configurations were transcribed from the ultrasonic blood flowmeter audio output signal to a strip chart recorder. The records given in Figure 8 demonstrate the pulsatile flow obtained in the axillary artery and venous flow (uninfluenced and with clenched fist) for both control and test conditions.

The ultrasonic flowmeter was always audible, and plainly visible on the oscilloscope. This was tested with differential pressures of 100 and 150 $\mathrm{mm} \mathrm{Hg}$. Regular venous flow sensed in the axilla with the ultrasonic flowmeter was difficult to detect but present at $150 \mathrm{~mm} \mathrm{Hg}$, and apparently absent at $200 \mathrm{~mm} \mathrm{Hg}$ differential pressure; however, venous flow was easily detected at all differential pressures when the subject flexed his arm or made a fist. The protection afforded by the elastic sleeve was at least sufficient to insure venous return when the arm muscles were tensed.

Another evidence of the effect of the sleeve comes from the subjective report of the sensation which occurs when the arm chamber is evacuated. After the sleeve is donned, the hand and arm are at some higher pressure than the rest of the body until the arm is placed in the arm chamber and a differential pressure produced. Ischemic pain can develop in five to ten minutes in this powerful elastic sleeve if the arm is not exposed to a low pressure. As the differential pressure was developed by the vacuum pump, there was a sensation of relief as if circulation were starting up again in previously deprived tissue. 
Figure 8. Axillary artery pulsatile blood flow and venous flow obtained with the Doppler ultrasonic flowmeter.

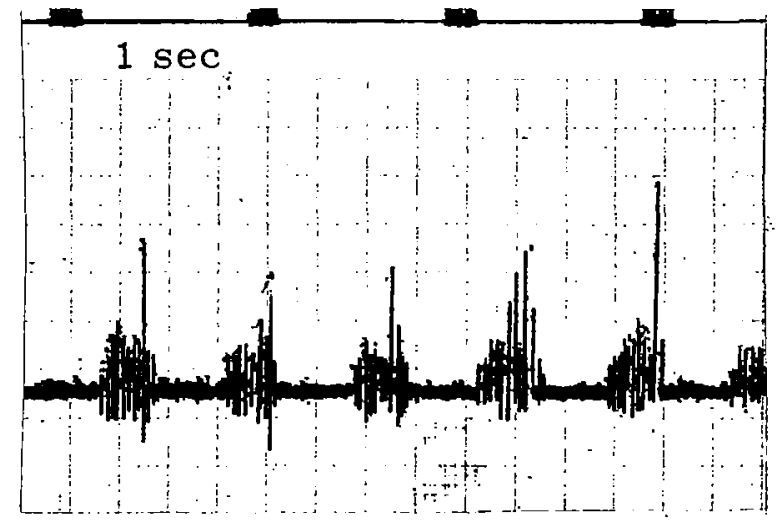

Arterial pulsatile flow-sleeve on; arm at zero $\Delta P$

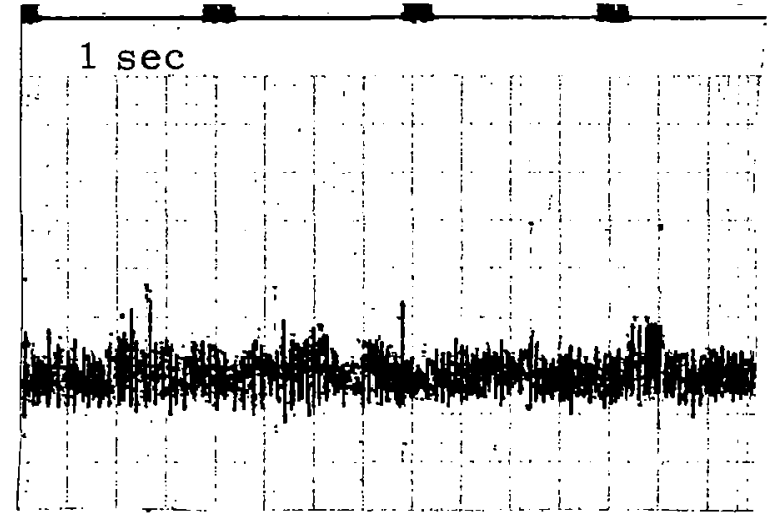

Venous flow--sleeve on; arm at zero $\Delta P$

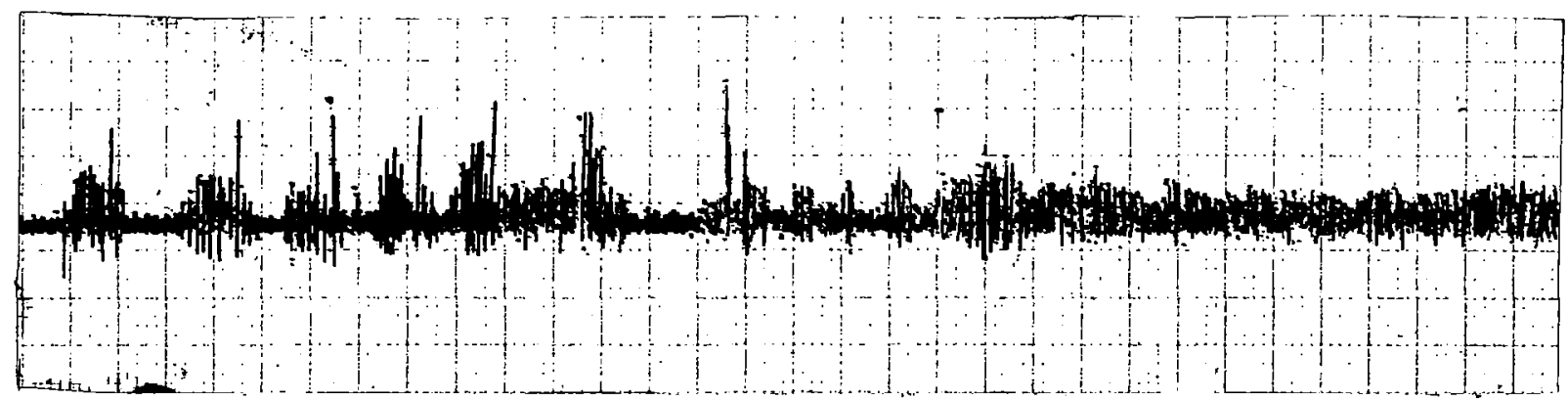

Arterial flow superimposed on venous flow, changing to increased venous flow on the right half of the record. Sleeve on and $\Delta \mathrm{P}$ of $150 \mathrm{~mm} \mathrm{Hg}$. 
Changes in arm volume were suspected following some of the early altitude runs with high differential pressures when the arm seal was poor and some tourniquet effect was clouding the picture. At the same time we discovered the thorough report of Ernsting (11) in which fluid filtation was described as one effect of raised intrapulmonary pressure. The subjective sensation of a change in arm volume is one of tightness and fullness. We learned that this was associated with a change in arm volume in excess of $5 \%$ of initial value. Using the final sleeve combination, we conducted a series of tests at ground level using differential pressures of 50,100,150, and $200 \mathrm{~mm}$ $\mathrm{Hg}$, and arm volume changes were also measured following the altitude tests at a differential pressure of $150 \mathrm{~mm} \mathrm{Hg}$. The results of these experiments are shown in Figure 9.

The swelling can be seen to increase with increasing differential pressure for a given protective garment. Increases in arm volume up to 5\% of initial value are not uncomfortable and do not limit motion in the arm. Since the elastic sleeve used in our experiments kept swelling below $5 \%$ at a differential pressure of $150 \mathrm{~mm} \mathrm{Hg}$, we suspect that its effective tissue pressure was somewhere between 50 and $100 \mathrm{~mm} \mathrm{Hg}$, with additional tissue pressure being developed by the elasticity of the skin and by fairly frequent tensing of the muscles of the arm and hand. While it would be desirable to have an elastic sleeve which delivered $150 \mathrm{~mm} \mathrm{Hg}$ of pressure to the tissue when the breathing pressure was $150 \mathrm{~mm} \mathrm{Hg}$, such a garment at present looks to be difficult to make, and heavy, and possibly limiting in mobility. We feel at present that the amount of swelling incurred in these experiments was acceptable. The swelling disappeared in three to four hours if it were less than $5 \%$, and within 24 hours if it were in the 8 to $10 \%$ range.

\section{CONCLUSIONS}

1. The principle of the Space Activity Suit has been tested successfully with a full glove and sleeve garment designed to deliver $100 \mathrm{~mm} \mathrm{Hg}$ pressure to the tissue, and which functionally appears to deliver between 50 and $100 \mathrm{~mm} \mathrm{Hg}$. There was no evidence of gas forming in the hand or arm when the arm was exposed to a near vacuum (less than $8 \mathrm{~mm} \mathrm{Hg}$ ). Circulation was adequate. Mobility, flexibility, and dexterity of the hand were excellent. There was no measurable increment in metabolic cost in wearing such a sleeve.

2. A vacuum environment is not necessary for testing this kind of suit. Differential pressures to protected limbs can be achieved with small chambers to give the same physiological effect. A full SA.S can be tested at ground level by using a regulator to deliver breathing gas at $150 \mathrm{~mm} \mathrm{Hg}$ positive pressure; in this circumstance the protective effect of limb counterpressure can be measured, and the suit can be tested for 
Figure 9. Change in A.rm Volume with Exposures to Increasing Differential Pressures for Twenty Minutes

(Normal total arm volume: average $2500 \mathrm{cc}$ to mid-deltoid)

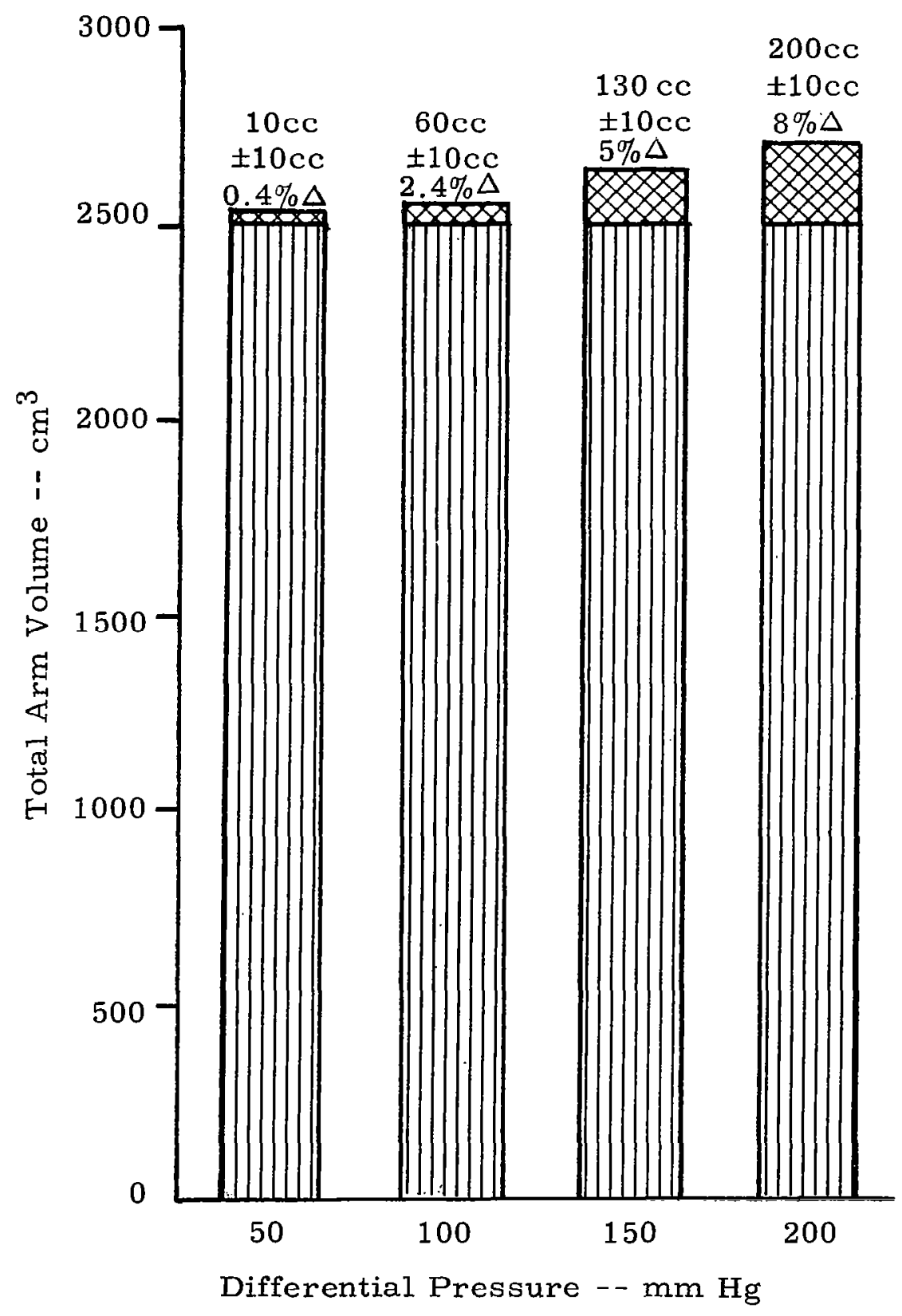

26. 
mobility, metabolic cost, etc. Vacuum chamber testing for a full SAS suit can be deferred until a late stage in the development of the full suit.

3. There is no present hindrance to the construction of a full SAS for laboratory testing. Problems to be overcome include developing sufficient hoop tension in the larger diameter segments of the body, improvement in ease of donning and tensioning of the elastic material, and assuring adequate circulatory balance for a four-hour period. Since the SAS is designed for an active person, testing should be done with much physical activity, which will help venous return in the same way it may be aided in actual use by an active astronaut in space.

4. The advantages seen in the SA.S approach, and partially proven in the experiments described here, include great improvement in mobility, flexibility and dexterity at small metabolic cost; simplicity in design approach; low risk to life from ripping or tearing the suit; easy and natural thermoregulation without power or additional cooling machinery.

5. A continuing full-scale development program should lead to a suit which will provide good protection for up to four hours in a vacuum for an astronaut who is able to carry out a full range of human activities with minimal life support equipment. 
1. GELL, CHARLES F., EDWARD L. HAYS, and JAMES V. CORREALE. Developmental history of the aviator's full pressure suit in the U.S. Navy. J. Aviat. Med. 30: 241-250, 1959.

2. BANCROFT, RICHARD W. and JAMES E. DUNN, II. Experimental animal decompressions to a near vacuum environment. Aerospace Med. 36: 720$725,1965$.

3. KOESTLER, ALFRED G., editor. The effect on the chimpanzee of rapid decompression to a near vacuum. NASA CR-329. National Aeronautics and Space Administration, Washington, D. C., 1965.

4. RUMBAUGH, DUANE M. and JOSEPH W. TERNES. Learning-set performance of squirrel monkeys after rapid decompression to vacuum.

Aerospace Med. 36:8-12, 1965.

5. COOKE, JULIAN P. and RICHARD W. BANCROFT. Some cardiovascular responses in anesthetized dogs during repeated decompressions to a near vacuum. Aerospace Med. 37: 1148-1152, 1966.

6. WILSON, CHARLES L. Production of gas in human tissues at low pressures. Report No. 61-105, School of Aerospace Medicine, USAF Aerospace Medical Center, Brooks Air Force Base, Texas, 1961.

7. ERNSTING, J., R. E. NAGLE, and D. J. PARRY. The boiling of tissue fluids at low barometric pressures. J. Physiol. 142: 50P, 1958.

8. HINRY, J.P., P. O. GREELEY, J.P. MEEHAN, and D. R. DRURY. A case of sudden swelling of the hands occurring at 58,000 feet simulated altitude. Comm. Av. Med. Report No. 393, National Research Council, Washington, D. C. , 1944.

9. McGUIRE, TERENCE F. Physiology and operational comparison of $\mathrm{MC}-1$ and MC-3 (MC-4) partial pressure suits. WADC Tech. Report 57-536 (I), Wright Air Development Division, Wright-Patterson Air Force Base, Ohio, 1960.

10. HENRY, J.P. and D.R. DRURY. Emergency pressure suit. AAF ATSC Engineering Division Memorandum Report No. TSEAA-660-100, 5 May 1946.

11. ERNSTING, JOHN. Some effects of raised intrapulmonary pressure in man. Technivision, Maidenhead, England, 1966.

12. HALE, FRANK C., RONALD A. WESTLAND, and CRAIG L. TAYLOR. The influence of barometric pressure and vapor pressure on insensible weight loss in nude resting man. WADC TR 57-9, Wright Air Development Center, Wright-Patterson Air Force Base, Ohio, 1957. 
13. WEBB, PAUL, LAURENS N. GARLINGTON, and MARVIN L. SCHWARZ. Insensible weight loss at high skin temperature. J.A.ppl. Physiol. 11: $41-44,1957$.

14. GAGGE, A. P., S. C. ALLEN, and J. P. MARBARGER. Pressure breathing. J. Aviat. Med. 16: 2-8, 1945.

15. JACOBS, H. J. and A. I. KARSTENS. Physiological evaluation of the partial pressure suit, part I. USAF Memorandum Report No. M CREXD696-104J, 1948.

16. WILSON, CHARLES L. Operational use of the United States Air Force partial pressure suit. Aerospace Med. 32: 825-828, 1961.

17. DAVIS, JEFFERSON C., FREDERICK R. RITZINGER, and LARRY E. NOBLE. Studies on an advanced passively pressurizing partial pressure suit. 286-287, Preprints, 1967 Annual Scientific Meeting, Aerospace Medical Association, Washington, D. C., 1967.

18. BARTER, JAMES T. A statistical evaluation of joint range data. WADC TN 57-311, Wright Air Development Center, Wright-Patterson Air Force Base, Ohio, 1957. 